\title{
The Effects of Managerial Values on Social Issues Evaluation: An Empirical Examination
}

\author{
MARK P. SHARFMAN \\ University of Oklahoma \\ TAMMIE S. PINKSTON \\ Andersen Consulting \\ THOMAS D. SIGERSTAD \\ University of Oklahoma
}

\begin{abstract}
This article suggests that due to the value-laden nature of social issues, managerial values, as a framework or schema, play an important role in the social issues evaluation process. Our data show that there is clearly a relationship between the issues managers evaluate as important and the values of those managers, with values being defined according to the Carroll typology-economic, legal, ethical, and philanthropic. It was apparent that the values held by the managers sampled determined how various sets of issues-community, political, and regulatory-were evaluated in terms of importance. This result suggests that the issues evaluation process, which should be objective, is not.
\end{abstract}

Within the field of strategic management, interest has been growing in how top managers receive, interpret, and evaluate information and how such interpretation results in top management action with respect to corporate performance (Dutton, Fahey, \& Narayanan, 1983; Dutton \& Jackson, 1987 ; Nystrom \& Starbuck, 1984). In the social issues management context, we are interested in the same question: How do managers make sense of social information and use it to influence corporate social performance? Although we are beginning to understand how managers interpret

AUTHORS' NOTE: Portions of this article were presented at the Academy of Management 1997 Annual Meeting. We wish to thank Steve Wartick and three anonymous reviewers for their assistance on this and earlier drafts of this article. 
strategic issues, we have relatively little information about how they receive, interpret, and evaluate social issues. Liedtka (1989) discusses individual and organizational value systems and their role in decision making. This article suggests that due to the value-laden nature of social issues, managerial values play an important role in the social issues evaluation process. We suggest that managerial values create a framework (Kahneman and Tversky, 1984) or a schema (Feldman, 1981; Gioia and Sims, 1986) within which managers make evaluations of social issues. It seems clear that values will play an important role in the identification stages of issues management when managers are filtering those issues that ultimately will receive their attention. We have, however, limited this article to a study of only the relationship between managerial values and the subsequent evaluation of social issues that have passed the identification stage.

We have evidence to suggest that managerial values play a major role in decision making in general and choices about social issues in particular. Fredrickson (1983) suggested that decision-making theory has paid too little attention to the impact of other personal and organizational values and beliefs on the decision-making process. Thomas and McDaniel (1990) suggested that if researchers hope to understand and improve strategic decision processes, "our understanding of what causes the same stimuli to be interpreted differently in different organizations should be a high-priority research question" (p. 287). Greening and Gray (1994) also report on assertions that "how decision makers interpret external events accounts for differences in responses" (p. 468). We think that the "how" is often at least partly due to those managerial values we seek to measure in this study. Greening and Gray (1994, p. 479) measure this idea in the form of top management "commitment" and help us define the construct with reference to "ideologies" (Gray, 1983), "beliefs" (Miles, 1987), and "the extent to which managers are personally invested in an organization's actions on issues" (Dutton \& Dukerich, 1991; Sutton \& Callahan, 1987). Greening and Gray find that this managerial commitment affects the way in which managers structure and formalize issues management activities. These beliefs, ideologies, personal investment, and commitment form what we term the "values" that managers hold and play an important role in the issues management process, specifically in the evaluation phase of issues management. (Many researchers choose to use terms that often others suggest offer some ambiguity. Concepts such as values and beliefs seem to imply something desirable and esteemed, whereas attitudes and ideologies refer to characteristic ways in which individuals or even organizations respond based, perhaps partially, on those values and beliefs.) 
Research about issues evaluation is complicated by the social context, which is highly complex and often ambiguous. This ambiguity and complexity impact the sensing of information as well as any resulting action(s). For instance, in the absence of absolute standards, issues managers must constantly monitor trends, subtle or otherwise, and recognize their implications for the company. When values shift, the effect ripples throughout related standards of performance. Changes in values and norms produce stress points between public and corporate interests (Heath \& Associates, 1988) and increase the likelihood of these changes becoming social issues that management must address.

It is this shifting of values that causes the greatest degree of ambiguity and complexity for the social context. In an attempt to provide some structure to the chaos of the social context, issues management evolved with implications for both research and practice; however, for the most part, the field of issues management and the broader field of social issues have primarily addressed values at the macro level. Values are understood as being those of the society at large. Prior research paid limited attention to the idea that individuals have their own value systems and individuals' values affect the issues management process.

Consistent with Heath and Associates (1988), our thesis for this article is that without absolute standards, the individual manager's value system will determine not only his or her monitoring and interpreting but also the evaluation of the social issues with which the organization has to contend. Recognizing that values enter well before the evaluation stage of issues management, specifically in the initial stages of issues identification, one should easily see how complex, perhaps individualized this process could become. It is increasingly clear that the meanings applied to issues differ depending on the perspectives considered of those doing the interpretation (Mahon \& Waddock, 1992).

Beside the fact that the relationship between values and issues evaluation represents a gap in the theory of issues management, we suggest that there is a rather pragmatic reason to study the relationship between values and issues evaluation. If we assume that values are intellectual and emotional constructs that are held to be important to individuals, we can move to Ajzen and Fishbein's (1977) suggestion that individuals create a structure of attitudes consistent with these values. Katz (1960) and others have suggested that attitudes provide people with a framework within which to interpret the world and integrate new experiences. Ajzen and Fishbein further suggested that by understanding an individual's attitudes toward something, one can predict that individual's "overall pattern of responses to the object" (p. 888) as new experiences occur. They argued that "a 
single behavior is determined by the intention to perform the behavior in question. A person's intention is in turn a function of his attitude towards performing the behavior" (p. 888).

Therefore, not only will managerial values frame the issues evaluation process but they are also likely to directly shape the issues management process as well. We propose that if we understand how values affect issues evaluation, we will have a much sounder basis on which to explain the issues management process as well. To further support this point, we turn to Liedtka (1989), who argued that "people behave in accordance with their own ideologies and values, and also in accordance with the ideologies and values of powerful superiors" (p. 56).

\section{Defining Issues and Issues Management}

Brown (1979) defined an issue as "a condition or pressure, either internal or external to the organization, that, if it continues, will have a significant effect on the functioning of the organization or its future interests" (p. 1). Due to the increasing number of issues, their complexity, and their accelerated impacts, both practitioners and academics during the past 20 years have begun to advocate efforts at managing such issues. However, Wartick and Rude (1986) suggest that "the most fundamental question in Issues Management (IM) is 'What is an issue?'” (p. 139).

In a more recent article, Wartick and Mahon (1994) reviewed the literature and presented a comprehensive definition of an issue. Reflecting changes in our understanding of the nature of social issues since Brown's work, these authors argue that a corporate issue (subsuming social, public policy, strategic issues, etc.) has the following four characteristics: (a) a controversial inconsistency based on one or more expectational gaps (b) involving management perceptions of changing legitimacy and other stakeholder perceptions of changing cost/benefit positions (c) that occur within or between views of what is and/or what ought to be corporate performance or stakeholder perceptions of corporate performance and (d) imply an actual or anticipated resolution that creates significant, identifiable present or future impact on the organization (p. 309). To make our article consistent with Wartick and Mahon (1994) and the need for formalism in developing "solid issues management theory" (p. 309), we adopt the above definition.

To define issues management, we turn to Chase (1982) who suggested that issues management is "the capacity to understand, mobilize, coordinate, and direct all strategic and policy planning functions, and all public affairs/public relations skills towards achievement of one objective: 
meaningful participation in creation of public policy that affects personal and institutional destiny" (in Heath \& Nelson, 1986, p. 20). Greening and Gray (1994) also offer a conceptualization of issues management based on Jones (1983) and Wartick and Rude (1986) as "a firm's identifying, analyzing, and responding to social and political concerns that can significantly affect it" (p. 467). These definitions have been widely accepted, but it is important not to confuse perceptions with the values that this article ultimately will measure. Perception (or awareness, cognition, and comprehension) is an early stage of the process of issues management. We seek to study the evaluation stage in which values, we argue, play an important role.

A related issue brought up by many is the disagreement about where the responsibility for issues management lies. Many researchers have argued that issues management should be integrated at all planning levels (e.g., Camillus \& Dalta, 1991; Heath \& Associates, 1988). All managers communicate with key publics periodically, and although they may not monitor issues closely, they must be sensitive to and assess the impact of issues on corporate performance. Each level of management potentially sets the tone for issues evaluation and activities to be implemented by others throughout the company. For our study, it is not important that we measure top management's values and issues evaluation relationships to understand the relationship of values and issues evaluation that the organization may have, but rather that for any manager we have a basis for suggesting that values and issues evaluation will be related. We examine this relationship at a higher managerial level because we understand that the tone for an organization's response to issues will be set at or near the top of the managerial hierarchy. However, it is equally important to show that a relationship may exist at any level in the organization. In research that looks at the values and issues evaluation relationship at earlier stages of issues management, this may be a critical finding as lower-level managers probably play a larger role in filtering and selectively allowing issues to rise to higher levels of management.

Several researchers have undertaken the task of developing a model or process discussion of issues management (Buchholz, 1982; Chase \& Chase, 1987; Coates, Jarratt, \& Heinz, 1986; King, 1987; Wartick \& Cochran, 1985). The general model of issues management progresses from identification to monitoring, analysis, planning, and implementing. Although the terminology may differ and some models may be more complex, what is common to each of these studies is that "Once key issues are identified, [issues managers] set priorities to determine how much time and resources will be allotted to dealing with each of them" (Tucker \& Trumpfheller, 1993, p. 36). 


\section{Strategic Issues and Management}

Although strategic issues are not the focus of the study, there are some similarities in attempting to identify such issues, and as we understand them, social issues are often seen as subsets of strategic issues. Understanding the strategic issues management process will help us clarify the social issues management process.

Strategic issues are trends, developments, and dilemmas that affect an organization as a whole and its position in its environment (Egelhoff, 1982). Strategic issues are most often classified as opportunities or threats (Dutton \& Ottensmeyer, 1987), are often ill-structured and ambiguous (Lyles, 1981), and require an interpretation effort (Daft \& Weick, 1984; Mintzberg, Raisinghani, \& Theoret, 1976; Thomas \& McDaniel, 1990). It is this problem of interpretation with which we are most concerned in the current study.

Mintzberg (1973) contended that top decision makers suffer from information overload. In response, there is a natural tendency to be selective in the information received and processed. Once this selection occurs, however, the decision maker has already begun to interpret the issues that enter the organizational decision-making process. Interpretation has been defined as an individual-level process wherein people attend to and ascribe meaningful labels to incoming information (Cantor \& Mischel, 1979; Smart \& Vertinsky, 1984; Taylor \& Fiske, 1978). Within the context of strategic decision making, the research on interpretation proposes that the way an issue is labeled or framed predisposes action in a particular direction (Dutton et al., 1983). For example, Thomas and McDaniel (1990), citing Ramaprasad and Mitroff (1984) and Lyles (1987), suggested that " ... what people know influences what they can know. Past experience, prior knowledge, and existing schemata create frameworks that are used to reduce ambiguity and create meaning" (p. 287). Hall (1984) refers to the "retained set" as providing frameworks for deciding what data to attend to and how to interpret those data (p. 907). Thomas and McDaniel (1990) “explored how an organization's strategy and the information processing structure of the top management team are related to the labels the organization's chief executive officer applies to strategic issues and the range of variables the CEO uses in the interpretation process" (p. 288). Beyer (1981) stated that organizations use ideologies and values to legitimate their activities and to justify their decisions to stakeholders.

Liedtka (1989) interpreted these individual and organizational factors as value systems. In her research, she developed two case studies to investigate the congruence between individual and corporate value systems 
within the framework of decision making. The study identified four mindsets in managerial decision making. Although harmony, or lack thereof, between the individual's and organization's values did not fit into the hypothesized decision process, there was a clear pattern of behavioral approaches used by managers to frame the situation, evaluate alternatives, and make recommendations.

\section{The Differences Between Strategic and Social Issues}

There is one way, however, in which social issues evaluation may be different from strategic issues evaluation. The social context does, by its own nature, elicit value judgments on the part of managers that are less a part of the strategic issues evaluation process. Although it can be argued that the evaluation process should be value-neutral (cf. Logsdon \& Palmer, 1988), we join a growing body of researchers who acknowledge the importance of individual value systems with respect to both issues identification and evaluation, be they strategic and/or social. Several writers have directly addressed the role of values in social issues evaluation. Bigelow, Fahey, and Mahon (1991) suggest that issues identification essentially may be a fight about values. Mahon and Waddock (1992) add that individuals are not blank slates when it comes to assessment (evaluation) of alternatives (p. 24). Finally, Liedtka (1989) suggests:

Yet, values influence-and may dominate-the selection of organizational goals, which in turn, form the criteria through which all decisions are "rationally evaluated." They also determine, as a result, the way in which the organizational member defines the problem in the first place, and who is considered to be a member of the "dominant coalition" in a satisficing model (Cyert \& March 1963). Values thereby form the "givens" and frame the possibilities before the rational and satisficing processes take over. (p. 59)

There is a growing consensus that values affect the issues management process throughout its various stages in both strategic and social issues areas. We argue that because of the value-laden nature of social issues, a manager's values are more clearly in his or her conceptual foreground when said managers are considering social issues than when they examine strategic issues.

In summary, we see from the strategic issues literature that management's values play a major role in the process. With respect to issues management, we suggest that the process for social issues should not be appreciably different from that of strategic issues. Within the process, however, 
we think values will have a larger effect on the evaluation of social issues than the evaluation of strategic ones. Our research is not designed to compare the relationship between strategic issues and managerial values with the relationship between social issues and managerial values but is designed to test whether the evaluation of social issues is indeed related to managerial values. Specifically, this project asks-do the values of the issues manager impact the issues evaluated as being important and, in turn, affect the priorities of those issues? We examined our research question through a mail survey, conducted with 132 chemical industry executives. We present the findings of this study following a discussion of the literature and methodology. We close the article with a discussion of the implications of our findings.

\section{THEORETICAL DEVELOPMENT}

From the preceding body of literature, we conclude that an individual decision maker's value system is integral to the process of social issues management, especially the stages of issues identification and, for our study, issues evaluation. The concepts underlying this project lead us to further specify our research questions as follows:

1. Are managers' values concerning social issues related to how they evaluate the importance of those issues?

2. How much do managers' values predict managers' evaluations of issue importance?

We propose that an individual manager's values create a framework (Kahneman and Tversky, 1984) or schema (Gioia and Sims, 1986) within which managers understand and evaluate social issues. Tversky and Kahneman (1981) argue that the relative attractiveness of options varies when the same decision is framed in different ways. As such, various social issues will appear more or less important depending on whether a particular manager finds the content of the social issue to be more or less consistent with his or her values. Whereas the present study does not presume to test explicitly whether managerial value structures form schemata or frameworks, the notion of a schema or framework gives us a strong theoretical foundation with which to underscore our investigation.

With the idea of a framework or schema in mind, we next needed a values classification consistent with social issues theory within which to develop our predictions about managerial social issues values. One social 
issues theoretical perspective that has been extended to address the values that managers hold and is widely accepted among social issues scholars is the one developed by Carroll (1979). This typology identifies four elements of a firm's activities (i.e., economic, legal, ethical, and philanthropic). (Carroll refers to philanthropic responsibilities as discretionary, although both terms are used throughout the literature in reference to Carroll's typology). In his theory, Carroll argues that each of the four areas represents elements of a firm's social responsibility. Each of these elements can be highly value laden. Aupperle (1982) extended the Carroll typology into an instrument that measures the preferences (degree of importance) that a given respondent places on each of the four Carroll elements. Again, because values concern concepts that we hold important and the Aupperle instrument identifies managerial values toward social issues, we selected it to operationalize the concept of managerial values concerning social issues.

Consistent with the idea of extending Carroll (1979) as a typology of managerial values, it is logical to assume that if a manager values a particular element of the typology highly (e.g., philanthropic), then he or she is likely to value philanthropic issues to a similar degree. However, Carroll also includes economic responsibilities. It is conceivable that if a manager places a very strong value on economic responsibilities, then he or she may limit the degree to which they value more social issues (i.e., ethical and philanthropic). We summarize these ideas below in a series of propositions:

Proposition 1: A manager has a mix of values at any point in time that helps the manager in making decisions about previously identified issues. The proportion of economic, legal, ethical, and philanthropic values at this point in time will determine how these issues are evaluated.

A manager who has a clear or significantly higher rating on a particular value scale could be identified as being, for example, an economic valuesoriented manager or a legal values-oriented manager. It may be possible that a manager might be characterized as having a very low values orientation in a particular area or having some mix or pairings of values orientations where certain values orientation groupings show emphasis and others are emphasized less. It is also possible that a manager has some indeterminate orientation based on values ratings that show no clear differences among values. In the hypotheses section below, we will use the values orientation idea to make predictions about managers' relative positions in terms of the values ratings. 
Proposition 2: The stronger a manager's economic values, the less importance that manager will place on legal, ethical, or philanthropic related issues.

These propositions organize our approach to our research questions. However, they are not testable. To develop testable hypotheses, we needed operationalized issues scales. We present a discussion of the development of our issues scales in the section below titled "Measures." We then present our specific predictions in the section titled "Hypotheses."

\section{METHODOLOGY}

\section{Data Collection}

The most cost-effective way to gather sufficient data to examine the research questions identified above is the mailed survey. Mailed surveys have the advantage of allowing the researcher to gather data from a wide variety of respondents while keeping costs low. Mailed surveys are especially appropriate when beginning the examination of a phenomena where established measures do not exist (Fowler, 1988), as is the case with the present research. Once we had decided on the method, it was necessary to choose the sample of managers. Arguments can be made for both broad and narrow samples. Getting a broad sample of managers from many industries gives better generalizability, but puts the study at risk of unmeasured industry differences affecting the results. By gathering data from managers in one industry, one loses some generalizability, but this approach reduces the possibility of industry effects explaining results. Given the ways that social issues management varies across industries (Littlejohn, 1986), we opted for a single industry sample of managers.

Choosing the specific industry within which to conduct this research required meeting several criteria for a larger study of which this article represents only a portion. First, it was important to select an industry in which there are a variety of social issues, and those issues vary in terms of their importance to member firms. It was also important that there be a large number of firms (and attendant managers) in the sample to give us confidence in our results. Finally, because the present project was part of a larger study on corporate social performance, several other criteria had to be met including variation in home country of ownership for the organization, although all firms were located in the United States. After reviewing all of the criteria mentioned above, the chemical industry was selected. This industry faces as wide a variety of social issues as virtually any 
industry. The issues of importance to this industry range from employee safety to pollution control to market regulation. There are also hundreds of firms listed in this industry in the United States. Using various archival sources, we developed a mailing list of 591 CEOs or presidents (if available) and general or plant managers in the case of subsidiaries from whom corporate data were not available. These managers received an initial mailed survey. After 3 weeks, nonrespondents received a follow-up survey form. In addition, 14 of 39 post office-returned surveys with forwarding addresses made available were re-sent. Total surveys received numbered 177. A total of 132 managers returned forms, of which 129 were complete enough to be used in the analysis, for a response rate of $22 \%$ for usable surveys. This response rate is comparable to similar surveys of senior executives (Ghoshal \& Nohria, 1989).

\section{Measures}

To investigate the propositions described previously, we needed scales to measure both the social values that managers hold and evaluations of the importance of various social issues. As we indicated above, the Aupperle (1982) instrument essentially extends Carroll's (1979) typology of social responsibility to the level of individual values. The Aupperle scale requires managers to allocate 10 points among items based on how they value each of these areas. Because the Aupperle scale has gained some degree of acceptance as evidenced by its use (e.g., Smith \& Blackburn, 1988), we adopted it for this study as our measure of managerial values (see Appendix 1).

Developing a scale to measure the importance of various social issues was more problematic. Although there is a great deal of theoretical material available concerning social issues management (e.g., Wartick \& Cochran, 1985; Wood, 1991), the empirical work that has been done in the area is diverse, and research examining the importance of various issues is essentially nonexistent. To develop the scale we used in this study, we conducted a review of the extant literature on social issues management. From this literature review, a comprehensive list of issue areas was constructed. To ensure that the list was comprehensive, it was reviewed by an expert panel of four academics well-versed in both research and practice in the area of issues management. Once agreement was reached on the set of items, the scale was then presented to a group of 15 chemical industry experts characterized by their top management team seniority and tenure within and familiarity with the chemical industry. These practitioners were asked to confirm that the issues the literature review had identified were of critical importance in the chemical industry. These experts were 
also asked to provide any additional issues that should be further explored. This process was accomplished through a pilot study in which a sample of organizations and industry experts was sent questionnaires and asked for comments and opinions. The test group was asked to validate the questionnaire and make changes that it considered appropriate. Once the pilot study was completed, we selected the final set of issues and included them in the final survey form. (See Appendix 2 for the list of the 16 items.) Each issue was measured on a scale from 1 to 4 with 1 being unimportant and 4 being critically important.

Using the 16 separate issues as individual dependent variables was neither practical nor methodologically sound. Because there were themes running through the literature from which the issues were taken, it was logical to assume that there would be similar themes in these data. To identify any structure underlying these 16 items, we conducted an exploratory factor analysis (EFA). We used EFA for several reasons. EFA is a widely used technique with easy application for the type of parametric data we have. Further, our data are all on the same metric and type of parametric scale so the assumptions of EFA would not be violated. The most important reason for using EFA to reduce the item set was that we had no theory to tell us how the items should fit together that confirmatory factor analysis (CFA) requires. Whereas CFA would have been preferable, without a theory to guide our analysis, CFA is inappropriate. Other data techniques such as cluster analysis also seemed inappropriate given that our purpose was construct scales, not to measure relative distances from means and so on. Using a principal components analysis with an oblique rotation, we extracted five factors initially. Because we have no evidence to suggest whether these factors should be independent or not, we chose not to force the structure to be orthogonal. Rather, we allowed the factors to correlate to see how independent they were. We present the factor structure and correlation matrices for both the complete list of items and the factors derived during the EFA in Tables 1, 2, and 3.

As one can see from Table 1, the factor structure was not perfectly "clean," (i.e., there were cross loadings that exceeded .5 for some factor pairs). To create a more usable factor structure, we used the following criteria: 1) all factor loadings must exceed $.5,2$ ) all .5 factor loadings must be positive, and 3) Cronbach's alpha statistic for any resulting factors must exceed the .60 convention for experimental scales (Hair, Anderson, Tatham, \& Black, 1998; Kim \& Mueller, 1978).

Criterion \#1 produced the five factors identified in the structure matrix whose items each have an asterisk. Criterion \#2 eliminated Factor 4 from consideration as a usable factor because one of the two $>.5$ loadings was negative. Criterion \#3 eliminated Factor 5 from consideration because this 
Table 1

Factor Analysis of the Social Issues Items

\begin{tabular}{lccccc}
\hline & Factor 1 & Factor 2 & Factor 3 & Factor 4 & Factor 5 \\
\hline & & & & & \\
\hline 1. Employee health and safety & & & & & \\
$\quad$ in the workplace & .05528 & $.55969^{\mathrm{a}}$ & .08386 & $.55619^{\mathrm{a}}$ & .28508 \\
2. Representation/participation & & & & & \\
$\quad$ of minorities & $.61011^{\mathrm{a}}$ & .43116 & .19046 & -.24547 & .40959 \\
3. Job security of employees & .43631 & -.05380 & .01214 & .09494 & $.74887^{\mathrm{a}}$ \\
4. Payment of a living wage & .11358 & .31772 & .02423 & -.36243 & $.65922^{\mathrm{a}}$ \\
5. Protection of personal privacy & .27623 & .24289 & .09906 & $-.77616^{\mathrm{a}}$ & .24969 \\
6. Environmental protection & .14044 & $.74917^{\mathrm{a}}$ & .17843 & -.08002 & .01153 \\
7. Contributions to philanthropy & $.78932^{\mathrm{a}}$ & -.08570 & .20959 & .00108 & .09869 \\
8. Community outreach & & & & & \\
$\quad$ programming & $.78990^{\mathrm{a}}$ & .01110 & .29108 & -.12549 & .19544 \\
9. Employee volunteerism & $.57965^{\mathrm{a}}$ & .11404 & .36753 & -.43110 & .13459 \\
10. Minority development & $.73613^{\mathrm{a}}$ & .40985 & .27270 & -.21578 & .14577 \\
11. Regulatory compliance & .00804 & $.75552^{\mathrm{a}}$ & .06200 & -.15619 & .13835 \\
12. Political action contributions & .40303 & -.12082 & $.67509^{\mathrm{a}}$ & .28327 & -.00625 \\
13. Adaptation to local business & & & & & \\
$\quad$ practices & .05334 & .08041 & $.55863^{\mathrm{a}}$ & .01464 & $.58652^{\mathrm{a}}$ \\
14. Local government incentives & .32166 & -.11667 & $.65533^{\mathrm{a}}$ & -.11902 & .29987 \\
15. Representation in Washington, & & & & & \\
$\quad$ D.C. & .20342 & .32319 & $.77757^{\mathrm{a}}$ & -.13001 & -.02021 \\
16. "Grass-roots" lobbying & .27700 & .23090 & $.83533^{\mathrm{a}}$ & -.07202 & -.01545 \\
Alpha & .79 & .75 & .61 & N/A & .46 \\
\hline Note: Factors not yet named & & & & & \\
\hline
\end{tabular}

Note: Factors not yet named.

a. Loadings $>.50$.

factor had an alpha statistic of .46 . The remaining three factors all have positive loadings greater than .5 , no cross loadings, and alpha statistics of $.79, .75$, and .61 , respectively. In terms of the independence of the factors, the highest correlation between any pair of the remaining factors is .27 and the lowest is .08 . These data suggest that although there is some association between the factors, we judged the association to be low to trivial.

For ease of discussion, we labeled the three factors as follows. We called Factor 1 "Community Issues." In this factor, we see issues such as minority representation and development, philanthropy, and volunteerism. We named Factor 2 "Regulatory Issues" because it contains references to employee health and safety, environmental protection, and regulatory compliance. We called Factor 3 "Political Issues" because it includes issues such as political action committee donations, local government incentives, and lobbying. 
Table 2

Item Correlation Matrix $(\mathrm{N}=131)$

\begin{tabular}{|c|c|c|c|c|c|c|c|c|c|c|c|c|c|c|c|c|}
\hline & 1 & 2 & 3 & 4 & 5 & 6 & 7 & 8 & 9 & 10 & 11 & 12 & 13 & 14 & 15 & 16 \\
\hline 1. & 1 & & & & & & & & & & & & & & & \\
\hline 2. & $.20 *$ & 1 & & & & & & & & & & & & & & \\
\hline 3. & .11 & $.30 * *$ & 1 & & & & & & & & & & & & & \\
\hline 4. & .10 & $.30 * *$ & $.40 * *$ & 1 & & & & & & & & & & & & \\
\hline 5. & -.15 & $.43^{* * *}$ & .05 & $.27^{* *}$ & 1 & & & & & & & & & & & \\
\hline 6. & $.29 * *$ & $.27 * *$ & .03 & .17 & $.18^{*}$ & 1 & & & & & & & & & & \\
\hline 7. & .00 & $.31 * *$ & $.31 * *$ & .03 & $.17^{*}$ & .00 & 1 & & & & & & & & & \\
\hline 8. & .05 & $.37 * *$ & $.34 * *$ & .12 & $.24 * *$ & .08 & $.50^{* * *}$ & 1 & & & & & & & & \\
\hline 9. & -.07 & $.28 * *$ & $.21 *$ & $.21 *$ & $.30 * *$ & .15 & $.37 * *$ & $.48^{* *}$ & 1 & & & & & & & \\
\hline 10. & .14 & $.63^{* *}$ & $.21^{*}$ & $.21 *$ & $.30^{* * *}$ & $.26^{* *}$ & $.43^{* *}$ & $.48^{* *}$ & $.38^{* *}$ & 1 & & & & & & \\
\hline 11. & $.31 * *$ & $.23^{* *}$ & -.02 & $.18^{*}$ & .17 & $.42^{* *}$ & -.01 & .00 & .14 & $.22 *$ & 1 & & & & & \\
\hline 12. & .08 & $.21^{*}$ & .09 & -.11 & -.06 & .09 & $.32 * *$ & $.28 * *$ & $.19 *$ & $.21 *$ & -.14 & 1 & & & & \\
\hline 13. & $.22 *$ & $.23^{* *}$ & $.21 *$ & .12 & $.20 *$ & .05 & .09 & .14 & .16 & .12 & .14 & $.29 * *$ & 1 & & & \\
\hline 14. & -.04 & $.23 * *$ & $.19^{*}$ & .04 & .15 & .04 & $.26 * *$ & $.31 * *$ & $.30 * *$ & $.23 * *$ & .04 & $.39 * *$ & $.40 * *$ & 1 & & \\
\hline 15. & .12 & $.18^{*}$ & -.01 & .16 & .11 & $.25^{* *}$ & .16 & $.23 * *$ & $.27 * *$ & $.30 * *$ & $.19^{*}$ & $.35 * *$ & $.25 * *$ & $.32 * *$ & 1 & \\
\hline 16. & .11 & $.19 *$ & .03 & .12 & .07 & $.24 * *$ & $.17 *$ & $.26^{* *}$ & $.34 * *$ & $.35 * *$ & .08 & $.46^{* * *}$ & $.28 * *$ & $.37 * *$ & $.72 * *$ & 1 \\
\hline
\end{tabular}

Note: To conserve space, items are represented by their number in Table 1.

* Significant at 05 .

** Significant at .01 
Table 3

Factor Correlation Matrix

\begin{tabular}{lrrcrc}
\hline & Factor 1 & Factor 2 & Factor 3 & Factor 4 & Factor 5 \\
\hline Factor 1 & 1 & & & & \\
Factor 2 & .08 & 1 & & & \\
Factor 3 & .27 & .09 & 1 & & \\
Factor 4 & -.12 & -.11 & -.03 & 1 & 1 \\
Factor 5 & .18 & .12 & .10 & -.06 & \\
\hline
\end{tabular}

\section{HYPOTHESES}

With the construction of our measure of each manager's evaluation of the importance of sets of social issues, we can now turn to the operationalization of our propositions into hypotheses. For each values orientation, we now make specific predictions about the relationship that will exist between that values orientation and each measure of social issues importance. In each subsection below, we summarize our arguments about these relationships and then state them as formal hypotheses.

Economic values. Consistent with both propositions, we suggest that a manager who has a strong set of economic values will put economic issues ahead of other, more social issues (Carroll, 1993). We accept as given that managers will have economic issues with which to contend. With that in mind, it would follow that managers with an economic values orientation will pay attention to economic issues. As such, managers holding these values are likely to place less importance on community issues because of the costs and uncertain returns on investments in such issues. Managers with strong economic values are also likely to place only a minimum or the required emphasis on regulatory issues. In the current environment, addressing regulatory pressures can be extremely costly and can distract managers from the pursuit of maximized profits. The same managers also are likely to put less emphasis on political issues because addressing such issues is likely to contribute very little to the "bottom line." It is important to note that we are not suggesting a disregard for noneconomic issues but rather that a differential will exist wherein managers holding other values orientations will emphasize social issues more than the economic valuesoriented manager. We summarize our perspective in the following hypotheses: 
Hypothesis 1: The economic values-oriented manager will emphasize (a) community issues less than the legal values-oriented manager, (b) community issues less than the ethical values-oriented manager, (c) community issues less than the philanthropic values-oriented manager, (d) regulatory issues less than the legal values-oriented manager, (e) regulatory issues less than the ethical values-oriented manager, (f) regulatory issues less than the philanthropic values-oriented manager, (g) political issues less than the legal values-oriented manager, (h) political issues less than the ethical values-oriented manager, and (i) political issues less than the philanthropic values-oriented manager.

It should be clear from the above hypotheses that our perspective is that an economic-values orientation will exercise prominence over all other values orientations. Managers with another values orientation, however, may evaluate issues differentially. The following discussion and hypotheses further develop the argument we presented concerning our first proposition.

Legal values. Managers with strong legal values will place compliance with the law and regulations above other things. It is likely that they will see community issues as less important because these are not among the specific legal responsibilities of the firm. Because regulations generally have the force of law behind them, it is likely that managers with strong legal values will place a high degree of importance on obeying these regulations. Participation in the political process, however, is likely to be of somewhat less importance because, although it is the way that laws are developed and changed, the outcome of the process holds more weight than the process itself. We summarize our predictions as follows:

Hypothesis 2: The legal values-oriented manager will emphasize (a) regulatory issues more than community issues, (b) political issues more than community issues, and (c) regulatory issues more than political issues.

Ethical values. When managers hold high ethical values, we suspect that because of their personal sense of rectitude, they may perceive that their firm has a social contract (Donaldson, 1982) and is required to respond to issues in its community. This same manager may perceive regulatory compliance as their duty and as such place a high degree of emphasis on regulatory issues. Finally, managers with strong ethical values may see political activities as somehow unclean or morally questionable and hence not place much emphasis on them. Again, we do not suggest a disregard of political issues, only a differential emphasis compared to community and regulatory issues. We, however, have no basis on which to predict a differential emphasis between community and regulatory 
issues for managers with a strong ethical values orientation. Our predictions for managers with high ethical values are as follows:

Hypothesis 3: The ethical values-oriented manager will emphasize (a) community issues more than political issues, (b) regulatory issues more than political issues, and (c) community issues equally with regulatory issues.

Philanthropic values. Managers with strong philanthropic values are likely to see the needs of the community and want their firms to help meet those needs. Further, managers with strong philanthropic values also may see regulatory compliance as their duty and place a high degree of emphasis on regulatory compliance. There is likely a recognition that regulatory requirements have been implemented to meet society's needs. Finally, they may believe that as citizens of a democratic society, firms are required to be active participants in the community's political process. We summarize this last set of predictions in the following hypothesis:

Hypothesis 4: The philanthropic-values-oriented manager will emphasize (a) community issues equally with regulatory issues, (b) community issues equally with political issues, and (c) political issues equally with regulatory issues.

\section{RESULTS}

We present the means, standard deviations, and Cronbach alpha values for all variables in Table 4. To test our hypotheses about the relationships among managers' values and managers' evaluation of the importance of the various social issues, we conducted a correlation analysis. We present the results of this analysis in Table 5. As one can see from the table of intercorrelations, our 12 possible predictions (4 with each of 3 issues factors) included five correlations that were significant at $p<.05$ and a sixth significant at $\mathrm{p}<.10$. The average absolute value of these significant correlations was .26 (range $=.15$ to .39 ), indicating a low to moderate relationship between managerial values and social issues importance.

In terms of the pattern of relationships, each values orientation was significantly related to at least one of the issues factors. Whereas a cursory overview of the coefficients gives us a fair idea of the support or lack thereof for our hypotheses, there are a number of nonsignificant coefficients that make this comparison problematic. Further, the tests of equality required by some of our hypotheses are mostly unanswerable. Creating confidence intervals around the coefficients solves the comparison problem in using nonsignificant coefficients. An equally direct way to test our 
Table 4

Descriptive Statistics of All Variables

\begin{tabular}{llcc}
\hline Variable & Mean & SD & $\alpha$ \\
\hline Community issues (Factor 1) & 2.27 & .51 & .79 \\
Regulatory issues (Factor 2) & 3.77 & .32 & .61 \\
Political issues (Factor 3) & 1.95 & .54 & .75 \\
Economic values & 3.27 & .85 & .93 \\
Legal values & 3.06 & .64 & .90 \\
Ethical values & 2.44 & .61 & .87 \\
Philanthropic values & 1.18 & .54 & .92 \\
\hline
\end{tabular}

Note: Issues scale: 1 = unimportant, 4 = critically important . Values scale: Values were assigned a point value with a possible range of 0 through 10 points per value with the total for the four values equaling 10 points.

hypotheses, however, is to perform tests of equality for each correlation pair in our hypotheses. These inference tests for correlation coefficients (Neter, Kutner, Nachtsheim, \& Wasserman, 1996) allow us to determine support or lack thereof for our hypotheses. Our null hypothesis is that the coefficients are equal. This is a test for Hypothesis $3 \mathrm{c}$ and each of the three subhypotheses for Hypothesis 4. The alternative hypothesis is that the coefficients are not equal, which partially tests the remaining hypotheses that are of the less-than or more-than construction. The direction (sign) of the coefficient and the confidence intervals established with the Fisher $z$ transformation used in tests of inference for correlation coefficients allow us to confirm whether the inequality is more than or less than. We made comparisons for each coefficient pair represented by our hypotheses using the Fisher $z$ transformation to determine a $z^{*}$ test statistic that was compared to the $z$ required by our alpha level of $.05(z=1.96$ for a twotailed test). We present the test of inference results in Table 6 .

The economic values orientation was significantly, negatively related to the community issues and regulatory issues as predicted. The economic values-oriented manager emphasized both community and regulatory issues less than managers of any other (legal, ethical, or philanthropic) values orientation. Not only did the tests for equality fail but also the direction as established by signs and confidence intervals clearly shows that these managers emphasize these issues less, supporting Hypotheses 1a through 1f. The relationship with political issues was also negative, but tests for equality were supported in terms of the emphasis compared to other values orientations. This means that our hypotheses suggesting that economic values-oriented managers would emphasize political issues less than managers holding other values orientations was not supported. Thus, 
Table 5

Correlation Matrix for the Dependent (Issues) and Independent (Values) Variables

\begin{tabular}{|c|c|c|c|c|c|c|c|}
\hline & $\begin{array}{l}\text { Community } \\
\text { Issues }\end{array}$ & $\begin{array}{l}\text { Regulatory } \\
\text { Issues }\end{array}$ & $\begin{array}{l}\text { Political } \\
\text { Issues }\end{array}$ & $\begin{array}{c}\text { Economic } \\
\text { Values }\end{array}$ & $\begin{array}{l}\text { Legal } \\
\text { Values }\end{array}$ & $\begin{array}{l}\text { Ethical } \\
\text { Values }\end{array}$ & $\begin{array}{c}\text { Philanthropic } \\
\text { Values }\end{array}$ \\
\hline Community issues (Factor 1) & $\begin{array}{c}1 \\
P= \\
N=131\end{array}$ & & & & & & \\
\hline Regulatory issues (Factor 2) & $\begin{array}{c}.213 \\
P=.015 \\
N=131\end{array}$ & $\begin{array}{c}1 \\
P= \\
N=131\end{array}$ & & & & & \\
\hline Political issues (Factor 3) & $\begin{array}{c}.432 \\
P=.000 \\
N=131\end{array}$ & $\begin{array}{c}.199 \\
P=.023 \\
N=131\end{array}$ & $\begin{array}{c}1 \\
P= \\
N=131\end{array}$ & & & & \\
\hline Economic values & $\begin{array}{c}-.390 \\
P=.000 \\
N=129\end{array}$ & $\begin{array}{c}-.249 \\
P=.004 \\
N=129\end{array}$ & $\begin{array}{l}-.083 \\
P=.348 \\
N=129\end{array}$ & $\begin{array}{c}1 \\
P= \\
N=130\end{array}$ & & & \\
\hline Legal values & $\begin{array}{c}-.033 \\
P=.709 \\
N=129\end{array}$ & $\begin{array}{c}.208 \\
P=.018 \\
N=129\end{array}$ & $\begin{array}{l}-.099 \\
P=.265 \\
N=129\end{array}$ & $\begin{array}{l}-.270 \\
P=.002 \\
N=130\end{array}$ & $\begin{array}{c}1 \\
P= \\
N=130\end{array}$ & & \\
\hline Ethical values & $\begin{array}{c}.177 \\
P=.044 \\
N=129\end{array}$ & $\begin{array}{c}.142 \\
P=.109 \\
N=129\end{array}$ & $\begin{array}{c}.030 \\
P=.733 \\
N=129\end{array}$ & $\begin{array}{l}-.569 \\
P=.000 \\
N=130\end{array}$ & $\begin{array}{c}-.361 \\
P=.000 \\
N=130\end{array}$ & $\begin{array}{c}1 \\
P= \\
N=130\end{array}$ & \\
\hline Philanthropic values & $\begin{array}{c}.357 \\
P=.000 \\
N=129\end{array}$ & $\begin{array}{c}-.004 \\
P=.966 \\
N=129\end{array}$ & $\begin{array}{c}.147 \\
P=.095 \\
N=129\end{array}$ & $\begin{array}{l}-.516 \\
P=.000 \\
N=130\end{array}$ & $\begin{array}{c}-.287 \\
P=.001 \\
N=130\end{array}$ & $\begin{array}{c}.159 \\
P=.070 \\
N=130\end{array}$ & $\begin{array}{c}1 \\
1 \\
N=130\end{array}$ \\
\hline
\end{tabular}


Table 6

Hypotheses Tests for Correlation Coefficients $(\alpha=.05)$

\begin{tabular}{|c|c|c|c|c|c|}
\hline & Correlation & $|z *|$ & & $\begin{array}{l}\text { Support for } \\
\text { Hypotheses }\end{array}$ & Confidence Interval \\
\hline \multicolumn{6}{|l|}{ Hypothesis 1: The economic values-oriented manager will emphasize } \\
\hline a: Community issues less than the legal values-oriented manager. & $-.39<-.03^{*}$ & 3.01 & $\mathrm{Ha}$ & $\mathrm{Y}$ & $-.62,-.10<-.07, .00$ \\
\hline b: Community issues less than the ethical values-oriented manager. & $-.39<.18$ & 4.69 & $\mathrm{Ha}$ & $\mathrm{Y}$ & $-.62,-.10<-.00, .34$ \\
\hline c: Community issues less than the philanthropic values-oriented manager. & $-.39<.36$ & 6.23 & $\mathrm{Ha}$ & $\mathrm{Y}$ & $-.62,-.10<.06, .60$ \\
\hline d: Regulatory issues less than the legal values-oriented manager. & $-.25<.21$ & 3.69 & $\mathrm{Ha}$ & $\mathrm{Y}$ & $-.47, .00<.00, .40$ \\
\hline e: Regulatory issues less than the ethical values-oriented manager. & $-.25<.14 *$ & 3.15 & $\mathrm{Ha}$ & $\mathrm{Y}$ & $-.47, .00<.00, .28$ \\
\hline f: Regulatory issues less than the philanthropic values-oriented manager. & $-.25<.00 *$ & 1.99 & $\mathrm{Ha}$ & $\mathrm{Y}$ & $-.47, .00<-.01, .00$ \\
\hline g: Political issues less than the legal values-oriented manager. & $-.08^{*}<-.10^{*}$ & 0.13 & Ho & $\mathrm{N}$ & $-.17, .00<-.20, .00$ \\
\hline h: Political issues less than the ethical values-oriented manager. & $-.08 *<.03 *$ & 0.90 & Ho & $\mathrm{N}$ & $-.17, .00<.00, .06$ \\
\hline i: Political issues less than the philanthropic-values oriented manager. & $-.08 *<.15$ & 1.84 & Ho & $\mathrm{N}$ & $-.17, .00<-.00, .29$ \\
\hline \multicolumn{6}{|l|}{ Hypothesis 2: The legal values-oriented manager will emphasize } \\
\hline a: Regulatory issues more than community issues. & $.21>-.03 *$ & 1.94 & Но & $\mathrm{N}$ & $.00, .40>-.07, .00$ \\
\hline b: Political issues more than community issues. & $-.10^{*}>-.03^{*}$ & 0.53 & Ho & $\mathrm{N}$ & $-.20, .00>-.07, .00$ \\
\hline c: Regulatory issues more than political issues. & $.21>-.10^{*}$ & 2.46 & $\mathrm{Ha}$ & $\mathrm{Y}$ & $.00, .40>-.20, .00$ \\
\hline \multicolumn{6}{|l|}{ Hypothesis 3: The ethical values-oriented manager will emphasize } \\
\hline a: Community issues more than political issues. & $.18>.03 *$ & 1.18 & Ho & $\mathrm{N}$ & $-.00, .34>.00, .06$ \\
\hline b: Regulatory issues more than political issues. & $.14 *>.03 *$ & 0.90 & Ho & $\mathrm{N}$ & $.00, .28>.00, .06$ \\
\hline c: Community issues equally with regulatory issues. & $.18=.14 *$ & 0.29 & Ho & $\mathrm{Y}$ & $-.00, .34=.00, .28$ \\
\hline \multicolumn{6}{|l|}{ Hypothesis 4: The philanthropic values-oriented manager will emphasize } \\
\hline a: Community issues equally with regulatory issues. & $.36=.00 *$ & 3.00 & $\mathrm{Ha}$ & $\mathrm{N}$ & $.06, .60=-.01, .00$ \\
\hline b: Community issues equally with political issues. & $.36=.15^{*}$ & 1.79 & Ho & Y & $.06, .60=-.00, .29$ \\
\hline c: Political issues equally with regulatory issues. & $.15^{*}=.00^{*}$ & 1.21 & Ho & $\mathrm{Y}$ & $-.00, .29=-.01, .00$ \\
\hline
\end{tabular}

a. $H o$ means $r$ s are equal. $H a$ means $r \mathrm{~s}$ are not equal. 
Hypothesis 1g, Hypothesis 1h, and Hypothesis 1i were not supported. The outcome of our hypothesis testing, from an exploratory point of view, suggests that the economic values orientation emphasizes political issues equally with each of the other values orientations.

Managers who held strong legal values orientations emphasized regulatory issues and political issues equally with community issues showing nonsupport for Hypotheses $2 \mathrm{a}$ and $2 \mathrm{~b}$. Perhaps the legal values orientation sees community as the source of regulatory and political issues and does not make distinctions between them. Supporting Hypothesis 2c, we found nonequality and direction showing that the legal values orientation emphasizes regulatory issues over political issues. This may point to the importance in emphasizing the outcome more than the process for legal oriented managers.

Managers who held strong ethical values orientations were as likely to place importance on community issues as they did with political ones and regulatory issues as they did with political ones. This was not as predicted. We hypothesized that only community issues would be equally emphasized with regulatory ones for the ethical values-oriented manager. Therefore, Hypotheses $3 \mathrm{a}$ and $3 \mathrm{~b}$ were not supported, but Hypothesis $3 \mathrm{c}$ was. It seems that the ethical values orientation emphasizes each of these issues equally.

Managers who evaluated themselves as having strong philanthropic values did not, as predicted, rate community issues equally with regulatory ones, offering no support for Hypothesis $4 \mathrm{a}$. As predicted, managers who placed a high value on philanthropic values emphasized community issues equally with political ones and political issues equally with regulatory ones, supporting Hypotheses $4 \mathrm{~b}$ and $4 \mathrm{c}$. Although this may seem an odd finding on the surface (if transitivity is assumed) to establish equality between community issues and regulatory ones, a review of the overlap for the confidence intervals clearly shows why there is no equality.

Now that we have established that managers' values are related to the evaluations of specific social issues, the next question is - how related are values and issues identification in general? Whereas the correlation analysis gives us an idea of how strongly the individual values measures are related to issues evaluations and how various values orientations will be represented by emphasis on different sets of issues, they do not provide a comprehensive view of the overall relationship of values to issues evaluation-especially in terms of explained variance. To examine the overall relationship and the level of explained variance, we regressed the four values orientation scores on each of the three issues scores. We present the results of these analyses in Tables 7, 8, and 9. As one can see from the tables, in the cases of the community and regulatory issues scales, we were 
Table 7

Regression Analysis of the Community Issues Variable

\begin{tabular}{lrrrrrrr}
\hline & df & \multicolumn{2}{c}{ SS } & \multicolumn{2}{c}{ MS } \\
\hline ANOVA $^{\mathrm{a}}$ & & & & & & \\
$\quad$ Regression & 4 & & 7.13 & & 1.78 & \\
$\quad$ Residual & 124 & & 26.50 & & .21 & \\
& & & & & & \\
Values Variable & $\mathrm{B}$ & SE B & Beta & $\mathrm{T}$ & Sig T & VIF \\
\hline Economic & -.48 & .16 & -.79 & -2.92 & .00 & 11.48 \\
Legal & -.34 & .17 & -.43 & -2.00 & .05 & 7.12 \\
Ethical & -.34 & .18 & -.41 & -1.89 & .06 & 7.37 \\
Philanthropic & -.10 & .18 & -.11 & -.58 & .58 & 5.30 \\
Constant & 5.84 & 1.64 & & 3.57 & .00 & \\
\hline
\end{tabular}

Note: $R^{2}=.21 ; S E=.46$.

a. $F=8.34$. Signif $F=.0000$.

Table 8

Regression Analysis of the Regulatory Issues Variable

\begin{tabular}{lrrrrrrr}
\hline & df & \multicolumn{2}{c}{ SS } & \multicolumn{2}{c}{ MS } \\
\hline ANOVA $^{\text {a }} \quad$ Regression & \multicolumn{2}{c}{1.33} & & .33 & \\
$\quad$ Residual & 124 & & 11.92 & & .10 & \\
& & & & & & \\
Values Variable & $\mathrm{B}$ & SE B & Beta & T & Sig T & VIF \\
\hline Economic & .01 & .11 & .02 & .06 & .95 & 11.48 \\
Legal & .16 & .11 & .33 & 1.44 & .15 & 7.12 \\
Ethical & .14 & .12 & .26 & 1.13 & .26 & 7.37 \\
Philanthropic & .04 & .12 & .06 & .32 & .75 & 5.30 \\
Constant & 2.87 & 1.10 & & 2.61 & .01 & \\
\hline
\end{tabular}

Note: $R^{2}=.10 ; S E=.31$.

a. $F=3.46$. Signif $F=.01$.

able to estimate equations with a significant overall $F$ statistic with low to moderate explanatory power as shown by the $\mathrm{R}^{2}$ statistics. This suggests that we have a reasonable model to use in explaining the emphasis on these two categories of issues if we know the values orientation of the manager. We did not find a significant model for explaining the emphasis on political issues. 
Table 9

Regression Analysis of the Political Issues Variable

\begin{tabular}{|c|c|c|c|c|c|c|}
\hline \multirow[b]{2}{*}{ ANOVA $^{\mathrm{a}}$} & \multirow[t]{2}{*}{ df } & \multicolumn{2}{|c|}{ SS } & \multicolumn{2}{|c|}{ MS } & \multirow[b]{5}{*}{$V I F$} \\
\hline & & \multirow{3}{*}{\multicolumn{2}{|c|}{$\begin{array}{r}1.79 \\
36.08\end{array}$}} & \multirow{3}{*}{\multicolumn{2}{|c|}{$\begin{array}{l}.45 \\
.29\end{array}$}} & \\
\hline Regression & 4 & & & & & \\
\hline Residual & 124 & & & & & \\
\hline Values Variable & B & SE B & Beta & $\mathrm{T}$ & Sig T & \\
\hline Economic & -.33 & .19 & -.50 & -1.69 & .09 & 11.48 \\
\hline Legal & -.36 & .20 & -.43 & -1.82 & .07 & 7.12 \\
\hline Ethical & -.34 & .21 & -.38 & -1.61 & .11 & 7.37 \\
\hline Philanthropic & -.18 & .21 & -.17 & -.86 & .39 & 5.30 \\
\hline Constant & 5.16 & 1.91 & & 2.70 & .01 & \\
\hline
\end{tabular}

Note: $R^{2}=.05 ; S E=.54$.

a. $F=1.54$. Signif $F=.20$.

\section{DISCUSSION}

Given the results of our study, we would have to conclude that the issues evaluation process is not value free. There is clearly a relationship between the issues evaluated as important and the values of the manager doing the evaluation. It was apparent that the values held by the managers sampled determined the extent to which various sets of issues-community, regulatory, political — were evaluated as being important. This result suggests that the issues evaluation process, which should perhaps be objective, is not. A large portion of our predictions about the relationships among managers' values and their evaluation of issues was supported in this data set. As we stated earlier in this paper, strategic and social issues enter the issues management process in very similar ways. A critical juncture, however, is the evaluation stage in which managerial values seem to play a much larger role when it comes to social issues because of their more value-laden character. We don't dispute in a normative sense what should or should not be, but rather that a relationship exists between managerial values and the subsequent issues that become prioritized by those managers. Researchers and organizations alike should be aware that issues management is thusly affected by values held by those involved in the process. Organizational stakeholders may also be concerned with this finding. If managerial values affect issues management, then stakeholders will want those values to be aligned with theirs. Having like-minded managers in the issues management process would likely benefit the cause of 
some stakeholders and not others. This is important to the stakeholder and the organization if there is a conflict of values among any member of a manager, stakeholder, and organization triad. If objectivity in the process is required, then this research suggests that the process needs to take into account the value-issue relationship potential.

Early in this article, we made a distinction between social and strategic issues as a way in which to segue from the management literature's emphasis on strategic issues to those of a more social nature. Largely this appears as a dichotomy between economic issues and a large group of other issues. This distinction is largely a factor of business's primary role as an institution in society. It seems that social issues include firms acting strategically to fulfill their role as a successful economic institution in society. However, strategic decisions can be oriented socially as well as economically. We are not attempting to create a dichotomy that suggests that economics belong to the strategic decision side and all other values orientations belong to the social side. There may be an interwoven, political economy type of framework-let's call it a social economy framework-where decisions can start from either end and be modified by the other. Social decisions can have an economic component, especially when it comes to justifying them to shareholders, or economic decisions can incorporate social strategies as well. Values orientations of managers (one of which is economic) help explain the issues management process through issue selection and evaluation. We have been concerned with the latter in this study while understanding that the former occurs earlier in the process.

It is important to recognize, as we mentioned in this article's opening paragraph, that the issues management process starts long before issues are evaluated. The social and cognitive literature discuss five information processing steps: selective attention and comprehension, encoding, storage and retention, information retrieval, and judgment (Lord, 1985). The information processing model explains perceptions and behavior of managers based on the aforementioned "heuristic or automatic processes associated with cognitive schema" (Lord, 1985, p. 89). Whereas our data can only be used to address the question of how the values orientations of managers relate to their subsequent evaluation (preferences and prioritizations) of issues, there is a very interesting and involved preliminary phase where those same values orientations affect issues management beginning with which issues will even receive attention. Using the information processing perspective, we can speculate that managers' values schemata filter issues determining which will gain the attention of managers. At some level, this incoming information might not even gain the status of being an issue because of the value schema of a given manager. We can further 
speculate that the manager's experience with similar information, influence from coworkers or superiors, and judgments concerning the outcomes of past issues management activities will affect encoding, storage and retention, and retrieval. None of this is measurable with our data set because we enter the information processing model at the judgment or evaluation stage. This represents a limitation of this study, but we have suggested throughout this article that values are likely to play a role during the entire process.

In a multivariate equation, the values that managers hold predict small albeit nontrivial amounts of the variance with respect to differences in perceived importance of the issues. Our findings indicate that additional research needs to further investigate the relationship between values and earlier stages of issues management to better understand the overall issues management process. It appears that social issues management may be an "enacted" (Weick, 1969) process in which managers select those issues that they believe are important and pay attention to them, even if they are not the correct ones. Greening and Gray (1994) found that the very structure of the organization's issues management process is determined by the manager's commitment to various issues. Values may become sources of bias within that process, framing the choices managers make in ways similar to the Tversky and Kahneman (1981) notion of the framing effect. Another interpretation is that managers begin the issues management process with their values as a schema (Gioia and Sims, 1986) for interpreting issues within that frame. Future research should examine more closely how this framing effect works.

There is also evidence from our results that the relationship between values and issues evaluation is not linear. This evidence surfaced when we examined the regressions for possible multicollinearity. After we ran the regressions, we automatically compared the regression results with those from the correlation analysis. As we discuss below, this examination suggested multicollinearity in the measures derived from the Aupperle scale. We used a technique called ridge regression to address the effects of multicollinearity on the regressions. In addition to addressing many of the multicollinearity problems, the ridge regressions also gave us evidence of nonlinear relationships among the independent and dependent variables. In those results, we find a good deal of variance explained by interaction terms using combinations of the independent variables. The suggestion is that linear explanations alone are insufficient and that there are significant nonlinear relationships that need to be confirmed by subsequent studies. It should be noted that in this article we have only reported results from the linear estimation of the models because as of now, we have no theory to explain why these interaction effects might be present. Greening and 
Johnson (1997) reported some results showing managerial characteristics that have curvilinear effects with regard to crisis management, so our nonlinear results are not without precedent. We also suggest below in our discussion of the reasons for multicollinearity that it is likely that managers operate with a mix of values in the issues management process. At this juncture, we chose not to go beyond the simple linear relationships and speculate on the interaction of values orientations to create additional hypotheses. As such, we have not tried to interpret these results or even report them. (Results are available from the first author.) What these nonlinear results suggest is that the relationship between values and social issues may be more complex than our current theories allow us to explain. Future research may wish to concentrate on these nonlinear relationships.

Of particular importance to future research is the fact that this study identified a methodological problem with respect to the Aupperle (1982) instrument. There is strong evidence that the instrument's scales are multicollinear. In this section, we describe our efforts to remediate the multicollinearity problem. The original regression equations that provided us with data suggesting instability in the coefficients gave us hints of other problems. It should be noted that this instability and any nonsignificance in parameter estimates does not affect the overall variance explained in the regression models. An understanding of parameter behavior does, however, provide us with valuable insight for improving our theory in the future. In all three of the equations, the coefficient on at least one variable flipped signs between the zero order correlation analysis and the regression analysis. There were a total of five sign flips in the 12 estimates of interest. It is possible that these equations showed flipped signs because confidence intervals were wide enough to contain zero and values on the opposite side of zero, which would have been implied by the nonsignificance in the hypothesis testing. There are also a number of nonsignificant parameter estimates in the regression runs, which suggests that we cannot be entirely confident about the sign of these estimates either. Although our goal in the regression runs was to determine the explanatory power of our models and not retest parameter estimates, the outcome of sign flipping suggested one additional diagnostic to rule out the possibility of multicollinearity-something that could cause instability in the regression estimates. Although sign flipping is not a sure measure of multicollinearity, it is a strong indicator that the problem is present (Neter, Wasserman, \& Kutner, 1985). Additional evidence of possible multicollinearity came from the intercorrelation analysis of the values orientation scales themselves (see Table 5). Table 5 shows correlations between the economic scale and the others ranging from -.27 to -.57 . Given the forced choice nature of the Aupperle scale and the consistent pattern of negative 
relationships between the economic value scale and the others, it seems that respondents may have used their evaluations of the economics items as an anchor and adjusted their responses to the other items accordingly. If this speculation is true, there would be a linear dependency among the variables-the precursor to multicollinearity. Conceptually, it is possible that all the values orientations might be related. We suspect that although pure values orientations are possible, it is much more likely that managers will have a mix of values orientations. At any one time, all of the values orientations may come into play in the issues management process as suggested in the regression equations. Although values may be related, there is no a priori reason to believe that the relationship is strong enough to cause multicollinearity. Only the hints from sign flipping pointed us in this direction and required us to use further diagnostics. The final body of evidence for multicollinearity came from the diagnostics that we ran as part of the regression. Neter et al. (1985) suggest three main multicollinearity diagnostic statistics, but the one they place the most stake in is the variance inflation factor (VIF). They suggest two rules of thumb that will be helpful in diagnosing multicollinearity. If the largest VIF is over 10 or the mean of the VIFs is over 1, then they suggest these conditions are indicative of serious multicollinearity. As one can see in Tables 7 through 9, the largest VIF in our equations is 11.48 and the mean VIF is 7.82 - both indicative of extremely serious multicollinearity. Neter et al. suggest two sets of approaches to attempt to remediate multicollinearity. The first set of procedures entails reparameterizing the data on which the regression has been run. We tried the various transformations and standardizations that Neter et al. suggest—none of which had any effect on the possibly unstable coefficients nor lowered the VIF scores to acceptable levels. A more potent approach to remediating multicollinearity is through an iterative analytic procedure known as ridge regression. Neter et al. (1985) describe ridge regression as follows: "ridge regression ... modif[ies] the method of least squares to allow biased estimators of the regression coefficients. When an estimator has only a small bias and is substantially more precise than an unbiased estimator, it may well be the preferred estimator since it will have a larger probability of being close to the true parameter value" (p. 394).

We estimated ridge regressions for each of the three issues scores. We present these data in Tables 10 through 12. The ridge regression equations show some success at overcoming the multicollinearity as indicated by reversing four of our original five flipped signs. However, three new sign flips occurred albeit all with parameters that were nonsignificant to begin with and therefore had confidence intervals wide enough to include the other sign. 
Because ridge regression is an iterative procedure that presents the researcher with a variety of options, an investigator has several choices as to how to present the results. As part of the ridge regression process, the SAS procedure codes the observations via a process of subtracting a standard value from each observation and then standardizing the new value by dividing by the mean. Because the choice of the best coding constant is not always obvious, the program provides results that show the standard error of the mean predicted Y values using either the default range of coding values or ones preselected by the researcher. One can select the best response surface for the equation by determining what coding value produces the smallest standard error. Interestingly enough, the smallest standard error in two of our three ridge regression equations came from using a coding value of zero. In the one case where another coding value produced the smallest standard error, using a coding value of zero for that equation only increased the standard error of the mean predicted Y value by .023 . Using the same coding value on all three equations would have increased the standard error of the other two mean predicted Y values by .063 and .12 , respectively. Given that using a zero coding value provided us with the least error in the predicted $\mathrm{Y}$ values, we report the uncoded results in this article.

As one can see from Tables 10 through 12, we had the best success with overcoming the multicollinearity problems with the ridge regression equation for the community issues variable. This model also remained significant and offered a moderately high level of variance explained. The regulatory issues model remained significant but did not help stabilize coefficients. It is important to remember that the parameter coefficients have wide enough confidence intervals not to cause alarm. The political issues model remained nonsignificant. It appears that managers may have used their evaluations of the economic component to anchor the accompanying issues, possibly as a result of the forced choice methodology. Although potential multicollinearity may be a concern when using the Aupperle instrument, the cause of the problem may also be representative of the decision-making process used by today's managers. Ask any practitioner and it is likely that they will indicate that without fulfilling their economic responsibility, no other responsibility can be upheld. Carroll (1993) summed up this position as follows:

Economic and financial issues have always been an inherent part of the business process .... The greatest growth has been in social, ethical, and political issues-all public issues that have high visibility and interest among stakeholder groups. We should also note that these issues become more interrelated over time. For most firms, social, ethical, political, and 
Table 10

Ridge Regression of the Community Issues Variable

\begin{tabular}{|c|c|c|c|c|c|c|c|c|}
\hline & & & & & $\begin{array}{c}\text { Response } \\
\text { Mean }\end{array}$ & $\begin{array}{l}\text { Root } \\
\text { MSE }\end{array}$ & \multicolumn{2}{|c|}{$\begin{array}{l}\text { Coefficient } \\
\text { of Variation }\end{array}$} \\
\hline \multicolumn{5}{|c|}{ Response surface for community issues variable } & 2.26 & \multicolumn{2}{|c|}{0.47} & 21.03 \\
\hline Regression & df & & SS & Type I SS & & $\mathrm{R}^{2}$ & F Ratio & $\mathrm{p}>\mathrm{F}$ \\
\hline \multicolumn{9}{|l|}{ Type } \\
\hline Linear & 4 & & & 6.29 & & 0.17 & 6.99 & .00 \\
\hline \multicolumn{9}{|l|}{ Residual } \\
\hline Lack of fit & 112 & & 25.54 & & 23 & & 4.56 & .20 \\
\hline Pure error & 2 & & 0.10 & & 05 & & & \\
\hline Total error & 114 & & 25.64 & & 22 & & & \\
\hline Parameter & & df & $P a$ & ameter Estimate & SE & & $\mathrm{T}$ for $H_{0}{ }^{\mathrm{a}}$ & $\mathrm{p}>|T|$ \\
\hline Intercept & & 1 & & -37.74 & 18.72 & & -2.02 & .05 \\
\hline Economic & & 1 & & -2.54 & 3.56 & & -0.71 & .48 \\
\hline Legal & & 1 & & 15.88 & 4.90 & & 3.24 & .00 \\
\hline Ethical & & 1 & & 11.18 & 5.63 & & 1.99 & .05 \\
\hline Philanthropic & & 1 & & 9.89 & 3.60 & & 2.75 & .01 \\
\hline
\end{tabular}

a. Parameter $=0$.

technological issues are at the same time economic issues because the firm's success in handling them frequently has a direct bearing on their financial status and well-being. (p. 578)

By developing an improved values instrument and examining the theoretical relationships among sets of issues and values, as well as the nonlinear components of this relationship, we gain a clearer understanding of the important relationships we discovered in this research.

These results have implications for practice as well. If managerial values bias an individual manager's evaluation of social issues, then effective issues management will require multiple managers involved in the evaluation process. Organizations face a real problem; regardless of how effective a particular manager is at enacting, there are likely to be some issues that are missed or somehow evaluated improperly. At least a portion of these issues will, in some capacity, affect the organization. We would recommend to practitioners that they devise multiple ways for overcoming such potential for bias in the evaluation stage of issues management. Everything possible should be done to avoid misspecification or misidenti- 
Table 11

Ridge Regression of the Regulatory Issues Variable

\begin{tabular}{|c|c|c|c|c|c|c|c|}
\hline & & & & $\begin{array}{c}\text { Response } \\
\text { Mean }\end{array}$ & $\begin{array}{l}\text { Root } \\
\text { MSE }\end{array}$ & \multicolumn{2}{|c|}{$\begin{array}{l}\text { Coefficient } \\
\text { of Variation }\end{array}$} \\
\hline \multicolumn{4}{|c|}{ Response surface for regulatory issues variable } & 3.75 & \multicolumn{2}{|c|}{0.34} & 8.97 \\
\hline Regression & df & SS & Type I SS & MS & $\mathrm{R}^{2}$ & F Ratio & $\mathrm{p}>\mathrm{F}$ \\
\hline \multicolumn{8}{|l|}{ Type } \\
\hline Linear & 4 & \multicolumn{2}{|r|}{1.26} & & 0.08 & 2.77 & .03 \\
\hline \multicolumn{8}{|l|}{ Residual } \\
\hline Lack of fit & 112 & 12.88 & & 0.11 & \multirow{3}{*}{\multicolumn{2}{|c|}{4.22}} & \multirow[t]{3}{*}{.21} \\
\hline Pure error & 2 & 0.05 & & 03 & & & \\
\hline Total error & 114 & 12.93 & & 0.11 & & & \\
\hline Parameter & df & $\mathrm{Pa}$ & ameter Estimate & SE & \multicolumn{2}{|r|}{$\mathrm{T}$ for $H_{0}^{\mathrm{a}}$} & $\mathrm{p}>|T|$ \\
\hline Intercept & \multicolumn{2}{|l|}{1} & 9.90 & 13.30 & \multicolumn{2}{|r|}{0.74} & .46 \\
\hline Economic & \multicolumn{2}{|l|}{1} & -3.83 & 2.53 & \multicolumn{2}{|r|}{-1.52} & .13 \\
\hline Legal & \multicolumn{2}{|l|}{1} & 0.76 & 3.48 & \multicolumn{2}{|r|}{0.22} & .83 \\
\hline Ethical & \multicolumn{2}{|l|}{1} & -2.95 & 4.00 & \multicolumn{2}{|r|}{-0.74} & .46 \\
\hline Philanthropic & \multicolumn{2}{|l|}{1} & 2.13 & 2.55 & \multicolumn{2}{|r|}{0.84} & .41 \\
\hline
\end{tabular}

a. Parameter $=0$.

fication of issues that could potentially lead to mismanagement. Consistent with Camillus and Dalta (1991), we suggest that using multiple observers and triangulating results in the issues evaluation process is one possible strategy. Camillus and Dalta suggest:

This stage [identification] requires considerable sensitivity and judgment on the part of those individuals involved, and to avoid the effects of individual biases, is best executed by a group of executives with adequate diversity in terms of their backgrounds, hierarchal levels, and functional areas. (p. 72)

By including more managers in the process, firms stand a much greater chance of accurately assessing the social issues they face and developing effective issues management strategies.

\section{LIMITATIONS}

This research has surfaced many more questions than it was designed to answer. This suggests that there are a few limitations to the study. One 
Table 12

Ridge Regression of the Political Issues Variable

\begin{tabular}{|c|c|c|c|c|c|c|c|}
\hline & & & & $\begin{array}{l}\text { Response } \\
\text { Mean }\end{array}$ & $\begin{array}{l}\text { Root } \\
\text { MSE }\end{array}$ & \multicolumn{2}{|c|}{$\begin{array}{l}\text { Coefficient } \\
\text { of Variation }\end{array}$} \\
\hline \multicolumn{4}{|c|}{ Response surface for political issues variable } & 1.97 & \multicolumn{2}{|c|}{0.54} & 27.33 \\
\hline Regression & df & SS & Type I SS & & $\mathrm{R}^{2}$ & F Ratio & $\mathrm{p}>\mathrm{F}$ \\
\hline \multicolumn{8}{|l|}{ Type } \\
\hline Linear & 4 & & 2.48 & & 0.05 & 2.14 & .08 \\
\hline \multicolumn{8}{|l|}{ Residual } \\
\hline Lack of fit & 112 & 32.74 & & & & 2.25 & .36 \\
\hline Pure error & 2 & 0.26 & & & & & \\
\hline Total error & 114 & 33.00 & & & & & \\
\hline Parameter & df & & meter Estimate & SE & & $\Gamma$ for $H_{0}{ }^{\mathrm{a}}$ & $\mathrm{p}>|T|$ \\
\hline Intercept & 1 & & -68.45 & 21.24 & & -3.22 & .00 \\
\hline Economic & 1 & & 11.52 & 4.04 & & 2.85 & .01 \\
\hline Legal & 1 & & 13.71 & 5.56 & & 2.47 & .02 \\
\hline Ethical & 1 & & 26.57 & 6.39 & & 4.16 & .00 \\
\hline Philanthropic & 1 & & 0.36 & 4.08 & & 0.09 & .93 \\
\hline
\end{tabular}

a. Parameter $=0$.

of those mentioned earlier is the level of management to which we can attribute the relationship we found. Whereas our intent was to reach a high level within the organization, we cannot confirm who actually filled out the questionnaire. We have addressed the idea of issues management having many stages and taking place at many management levels with the suggestion that the important point is that a relationship exists between values and issues. It may very well be that this relationship is different at stages of issues management other than the evaluation stage and that this relationship may be partially determined by the level of management involved at that stage.

Another potential limitation is that we tested manager's values and issues prioritization with the same instrument. Future researchers may wish to ascertain outcomes measured independently of the manager's self-reported opinion. Such measures might include time or money spent on issues to gauge how important they really are-data that were not available to our study. Self reports also have the tendency to be biased toward 
what might be considered the acceptable response as well as one that is consistent with the manager's earlier responses. We think that the social desirability bias suggested by such acceptable responses was not strong as evidenced by the full range of answers chosen by respondents and the relatively large standard deviations we found with the scales.

We also elected not to include controls for organizational size, profitability, or firm strategy. Our supposition was that these differences would be embedded in the economic values of the manager. Those values instilled partly through exposure to other managers, including superiors passing down a framework for the economic values that would be acceptable in that organization. To include controls may have improved the model's performance, but if there were overlap leading to multicollinearity the coefficients of interest would be unreliable measures. A charge for future research would be to determine the composition of economic values and if they did in fact measure firm characteristics.

Finally, because of the focus on managers in the chemical industry, it is not clear how generalizable our results are. However, given the breadth of issues that managers in this industry face, we feel reasonably confident that our data fairly represent this industry and that managers in other industries likely behave similarly.

\section{CONCLUSION}

This research identifies the relationship between the values a manager holds and how that manager evaluates issues that he or she confronts. The relationships suggested by the support for our hypotheses are an important first step. Those relationships are likely to be more complicated as suggested by the discussion of economic values anchoring the evaluations of issues. Further, the initial results from the nonlinear examination of the relationships suggest that a much more complicated set of dynamics may govern how managers' values affect their issues evaluations. Future research can both clarify and extend the results we found. It is clear, however, that the social issues management process, which should be objective, occurs not objectively, but rather as a function of the values held by the managers engaged therein. 


\section{APPENDIX 1}

The Aupperle Scale Questionnaire

Please answer each question, even if your knowledge on some items is limited or second-hand.

Based on their relative importance and application to your subsidiary, please allocate up to, but not more than, 10 points to each set of four statements (1 represents the least degree of importance). For example, you might allocate points to a set of statements as follows:

$$
\begin{aligned}
& \mathrm{A}=2 \quad \mathrm{~A}=1 \\
& \mathrm{~B}=4 \quad \mathrm{~B}=2 \\
& \mathrm{C}=1 \quad \text { or } \quad \mathrm{C}=0 \\
& \mathrm{D}=3 \quad \mathrm{D}=7 \\
& \text { Total }=10 \quad \text { Total }=10
\end{aligned}
$$

1. It is important to perform in a manner consistent with:

A. expectations of maximizing earnings per share.

B. expectations of government and the law.

C. the philanthropic and charitable expectations of society.

D. expectations of societal mores and ethical norms.

2. It is important to be committed to:

A. being as profitable as possible.

B. voluntary and charitable activities.

C. abiding by laws and regulations.

D. moral and ethical behavior.

3. It is important to:

A. recognize that the ends do not always justify the means.

B. comply with various federal regulations.

C. assist the fine and performing arts.

D. maintain a strong competitive position.

4. It is important that:

A. legal responsibilities be seriously fulfilled.

B. long-term return on investment is maximized.

C. managers and employees participate in voluntary/charitable activities in their local communities.

D. when securing new business, promises are not made that are not intended to be fulfilled.

5. It is important to:

A. allocate resources on their ability to improve long-term profitability.

B. comply promptly with new laws and court rulings.

C. examine regularly new opportunities and programs that can improve urban and community life.

D. recognize and respect new or evolving ethical/moral norms adopted by society. 
6. It is important to:

A. provide assistance to private and public educational institutions.

B. ensure a high level of operating efficiency to be maintained.

C. be a law-abiding corporate citizen.

D. advertise goods and services in an ethically fair and responsible manner.

7. It is important to:

A. pursue those opportunities that will enhance earnings per share.

B. avoid discriminating against women and minorities.

C. support, assist, and work with minority-owned businesses.

D. prevent social norms from being compromised to achieve corporate goals.

8. It is important that a successful firm be defined as one that:

A. is consistently profitable.

B. fulfills its legal obligations.

C. fulfills ethical and moral responsibilities.

D. fulfills its philanthropic and charitable responsibilities.

9. It is important to monitor new opportunities that can enhance the organization's:

A. moral and ethical image in society.

B. compliance with local, state, and federal statutes.

C. financial health.

D. ability to solve social problems.

10. It is important that good corporate citizenship be defined as:

A. doing what the law expects.

B. providing voluntary assistance to charities and community organizations.

C. doing what is expected morally and ethically.

D. being as profitable as possible.

11. It is important to view:

A. philanthropic behavior as a useful measure of corporate performance. B. consistent profitability as a useful measure of corporate performance.

C. compliance with the law as a useful measure of corporate performance.

D. compliance with norms/unwritten laws of society as useful measures of corporate performance.

12. It is important to:

A. recognize that corporate integrity/ethics go beyond mere compliance with laws/regulations.

B. fulfill all corporate tax obligations.

C. maintain a high level of operating efficiency.

D. maintain a policy of increasing charitable and voluntary efforts over time. 
13. It is important to:

A. assist voluntarily those projects that enhance a community's quality of life.

B. provide goods and services that at least meet minimal legal requirements.

C. avoid compromising societal norms and ethics to achieve goals.

D. allocate organizational resources as efficiently as possible.

14. It is important to:

A. pursue only those opportunities that provide the best rate of return.

B. provide employment opportunities to the hard-core unemployed.

C. comply fully and honestly with enacted laws, regulations, and court rulings.

D. recognize that society's unwritten laws and codes can often be as important as the written.

15. It is important that:

A. philanthropic and voluntary efforts continue to be expanded consistently over time.

B. contract and safety violations are not ignored to complete or expedite a project.

C. profit margins remain strong relative to major competitors.

D. whistle blowing not be discouraged at any corporate level.

\section{APPENDIX 2}

The Social Issues Scales

Using the scale provided, please indicate by circling the appropriate number, the degree of importance your subsidiary places on the following issues:

$1=$ Unimportant

$2=$ Somewhat important

$3=$ Very important

$4=$ Critically important

Employee health and safety in the workplace Representation/participation of minorities

Job security of employees

Payment of a living wage

Protection of personal privacy

Environmental protection

Contributions to philanthropy

Community outreach programming

Employee volunteerism

Minority development

$\begin{array}{llll}1 & 2 & 3 & 4 \\ 1 & 2 & 3 & 4 \\ 1 & 2 & 3 & 4 \\ 1 & 2 & 3 & 4 \\ 1 & 2 & 3 & 4 \\ 1 & 2 & 3 & 4 \\ 1 & 2 & 3 & 4 \\ 1 & 2 & 3 & 4 \\ 1 & 2 & 3 & 4 \\ 1 & 2 & 3 & 4\end{array}$


Regulatory compliance

Political action contributions

Adaptation to local business practices

Local government incentives

Representation in Washington, D.C.

"Grass-roots" lobbying

$\begin{array}{llll}1 & 2 & 3 & 4 \\ 1 & 2 & 3 & 4 \\ 1 & 2 & 3 & 4 \\ 1 & 2 & 3 & 4 \\ 1 & 2 & 3 & 4 \\ 1 & 2 & 3 & 4\end{array}$

\section{REFERENCES}

Ajzen, I., \& Fishbein, M. (1977). Attitude-behavior relations: A theoretical analysis and review of empirical research. Psychological Bulletin, 84(5), 888-918.

Aupperle, K. E. (1982). An empirical inquiry into the social responsibilities as defined by corporations: An examination of various models and relationships (Doctoral dissertation, University of Georgia, 1982). Dissertation Abstracts International, 43(6), 2023A.

Beyer, J. (1981). Ideologies and values and decision-making in organizations. In P. C. Nystrom \& W. H. Starbuck (Eds.), Handbook of organizational design: Vol. 2 (pp. 166-202). New York: Oxford University Press.

Bigelow, B., Fahey, L., \& Mahon, J. F. (1991). Political strategy and issues evolution: A framework for analysis and action. In K. Paul (Ed.), Contemporary issues in business and politics (pp. 1-26). Lewiston, NY: Edwin Mellen Press.

Brown, J. K. (1979). This business of issues: Coping with the company's environment. New York: The Conference Board.

Buchholz, R. A. (1982). Business environment and public policy. Englewood Cliffs, NJ: Prentice Hall.

Camillus, J. C., \& Dalta, D. K. (1991). Managing strategic issues in a turbulent environment. Long Range Planning, 24, 67-74.

Cantor, N., \& Mischel, W. (1979). Prototypes in person perception. In L. Berkowitz (Ed.), Advances in experimental psychology: Vol. 12 (pp. 4-52).

Carroll, A. B. (1979). A three dimensional model of corporate social performance. Academy of Management Review, 4, 497-505.

Carroll, A. B. (1993). Business \& society. Cincinnati, OH: Southwestern Publishing.

Chase, W. H. (1982, December 1). Issue management conference-A special report. Corporate Public Issues and Their Management, 7, 1-2.

Chase, W. H., \& Chase, T. H. (1987). Social (and other) issue management. In S. P. Sethi \& C. M. Falbe (Eds.), Business and society: Dimensions of conflict and cooperation (pp. 52-62). Lexington, MA: Lexington Books.

Coates, J. F., Coates, V. T., Jarratt, J., \& Heinz, L. (1986). Issues and management. Mt. Airy, MD: Lomond Publishing.

Cyert, R. M., \& March, J. G. (1963). A behavioral theory of the firm. Englewood Cliffs, NJ: Prentice Hall.

Daft, R. L., \& Weick, K. E. (1984). Toward a model of organizations as interpretive systems. Academy of Management Review, 9, 284-295.

Donaldson, T. (1982). Corporations and morality. Englewood Cliffs, NJ: Prentice Hall.

Dutton, J. E., \& Dukerich, J. M. (1991). Keeping an eye on the mirror: Image and identity in organizational adaptation. Academy of Management Journal, 34, 517-554. 
Dutton, J. E., Fahey, L., \& Narayanan, U. K. (1983). Toward understanding strategic issues diagnosis. Strategic Management Journal, 4, 307-323.

Dutton, J. E., \& Jackson, S. E. (1987). Categorizing strategic issues: Links to organizational actions. Academy of Management Review, 12, 76-90.

Dutton, J. E., \& Ottensmeyer, E. (1987). Strategic issues management systems: Form, functions, and contexts. Academy of Management Review, 12, 355-365.

Egelhoff, W. G. (1982). Strategy and structure in multinational corporations: An information-processing approach. Administrative Science Quarterly, 27, 435-450.

Feldman, J. (1981). Beyond attribution theory: Cognitive processes in performance appraisal. Journal of Applied Psychology, 66, 127-148.

Fowler, E. (1988). Survey research methods. Beverly Hills, CA: Sage Publications.

Fredrickson, J. W. (1983). Strategic process research: Questions and recommendations. Academy of Management Review, 8, 565-575.

Ghoshal, S., \& Nohria, M. (1989). Internal differentiation within multi-national corporations. Strategic Management Journal, 10, 323-339.

Gioia, D., \& Sims, H. P. (1986). The thinking organization. San Francisco: Jossey-Bass.

Gray, B. (1983). A preliminary theory of compliance with OSHA regulation. In L. Preston (Ed.), Research in corporate social performance (pp. 121-139). Greenwich, CT: JAI Press.

Greening, D. W., \& Gray, B. (1994). Testing a model of organizational response to social and political issues. Academy of Management Journal, 37(3), 467-498.

Greening, D. W., \& Johnson, R. A. (1997). Managing industrial and environmental crises. Business \& Society, 36(4), 334-361.

Hair, J. F., Jr., Anderson, R. E., Tatham, R. L., \& Black, W. C. (1998). Multivariate data analysis (5th ed.). Upper Saddle River, NJ: Prentice Hall.

Hall, R. I. (1984). The natural logic of management policy-making: Its implications for the survival of the organization. Management Science, 30, 905-927.

Heath, R. L., \& Associates. (1988). Strategic issues management: How organizations influence and respond to public interests and policies. San Francisco: Jossey-Bass.

Heath, R. L., \& Nelson, R. A. (1986). Issues management: Corporate public policymaking in an information society. Beverly Hills, CA: Sage Publications.

Jones, J. (1983). What are the issues? Business Quarterly, 22(3), 22-31.

Kahneman, D., \& Tversky, A. (1984). Choice, values, and frames. American Psychologist, 39, 341-350.

Katz, D. (1960). The functional approach to the study of attitudes. Public Opinion Quarterly, 24(2), 163-204.

Kim, J., \& Mueller, C. W. (1978). Factor analysis: Statistical methods and practical issues. Newbury Park, CA: Sage Publications.

King, W. R. (1987). Strategic issues management. In W. R. King \& D. I. Cleland (Eds.), Strategic planning and management handbook (pp. 252-264). New York: Van Nostrand Reinhold.

Liedtka, J. (1989). Managerial values and corporate decision-making: An empirical analysis of value congruence in two organizations. Research in Corporate Social Performance and Policy, 11, 55-91.

Littlejohn, S. E. (1986). Competition and cooperation: New trends in corporate public issues identification and resolution. California Management Review, 29(1), 109-123.

Logsdon, J. M., \& Palmer, D. R. (1988). Issues management and ethics. Journal of Business Ethics, 7, 191-198. 
Lord, R. G. (1985). An information processing approach to social perceptions, leadership and behavioral measurement in organizations. Research in Organizational Behavior, 7 , 87-128.

Lyles, M. A. (1981). Formulating strategic problems: Empirical analysis and model development. Strategic Management Journal, 2, 61-75.

Lyles, M. A. (1987). Defining strategic problems: Subjective criteria of executives. Organizational Studies, 3, 263-280.

Mahon, J. F., \& Waddock, S. A. (1992). Strategic issues management: An integration of issue life cycle perspectives. Business \& Society, 31, 19-32.

Miles, R. H. (1987). Managing the corporate social environment. Englewood Cliffs, NJ: Prentice Hall.

Mintzberg, H. (1973). Strategy making in three modes. California Management Review, 16, 44-53.

Mintzberg, H., Raisinghani, D., \& Theoret, A. (1976). The structure of "unstructured" decisions. Administrative Science Quarterly, 21, 246-275.

Neter, J., Kutner, M. H., Nachtsheim, C. J., \& Wasserman, W. (1996). Applied linear statistical models (4th ed.). Boston: WCB/McGraw-Hill.

Neter, J., Wasserman, W., \& Kutner, M. E. (1985). Applied linear statistical models, regression, analysis of variance, and experimental designs (2nd ed.). Homewood, IL: R. D. Irwin.

Nystrom, P. C., \& Starbuck, W. H. (1984). To avoid organizational circles, unlearn. Organizational Dynamics, 12, 53-65.

Ramaprasad, A., \& Mitroff, I. I. (1984). On formulating strategic problems. Academy of Management Review, 9, 597-605.

Smart, C., \& Vertinsky, I. (1984). Strategy and the environment: A study of response to crises. Strategic Management Journal, 5, 199-214.

Smith, W. J., \& Blackburn, R. S. (1988). CSR: A psychometric examination of a measurement instrument. Proceedings of the Southern Management Association, 293-295.

Sutton, R. I., \& Callahan, A. L. (1987). The stigma of bankruptcy: Spoiled organizational image and its management. Academy of Management Journal, 30, 405-436.

Taylor, S. E., \& Fiske, S. T. (1978). Salience, attention and attribution: Top of the head phenomena. In L. Berkowitz (Ed.), Advances in experimental social psychology, 11, 249-288.

Thomas, J. B., \& McDaniel, R. R. (1990). Interpreting strategic issues: Effects of strategy and the information-processing structure of top management teams. Academy of Management Journal, 33, 286-306.

Tucker, K., \& Trumpfheller, B. (1993). Building and issues management system. Public Relations Journal, 49(11), 36-41.

Tversky, A., \& Kahneman, D. (1981). The framing of decisions and the psychology of choice. Science, 211(4481), 453-458.

Wartick, S. L., \& Cochran, P. L. (1985). The evolution of the corporate social performance model. Academy of Management Review, 10, 758-769.

Wartick, S. L., \& Mahon, J. F. (1994). Toward a substantive definition of the corporate issue construct. Business \& Society, 33(3), 293-311.

Wartick, S. L., \& Rude, R. E. (1986). Issues management: Corporate fad or corporate function? California Management Review, 29(1), 124-140.

Weick, K. E. (1969). The social psychology of organizing. Reading, MA: Addison-Wesley.

Wood, D. (1991). Corporate social performance revisited. Academy of Management Review, 16(4), 691-718. 
Mark P. Sharfman is an associate professor of strategic management in the Michael F. Price College of Business at the University of Oklahoma. His articles on environmental management, corporate social performance, and strategic management have appeared in the Academy of Management Journal, Academy of Management Review, Business and Society, Business Horizons, Corporate Environmental Strategies Decision Sciences, Journal of Business Ethics, Journal of Industrial Ecology, Journal of Management, Journal of Management Studies, and the Strategic Management Journal. His research has been supported through grants from the Environmental Protection Agency and the National Science Foundation.

Tammie S. Pinkston received her Ph.D. in strategic management from the University of Georgia in 1991. A paper from her dissertation, titled "Corporate Citizenship: A Comparative Analysis of Foreign Affiliates Located in the United States and Their Domestic Counterparts”, was published in the Academy of Management Best Paper Proceedings 1992. In addition, she has published articles in the Journal of Business Ethics, plus the edited volumes Business and Society in a Changing World Order and Foreign Ownership and the Consequences of Direct Investment in the United States. She was an assistant professor at the University of Oklahoma from 1991 to 1994 and then went to work for Andersen Consulting, where she is currently a manager in the change management practice. Her market specialization is telecommunications, specifically focusing on PeopleSoft Financials implementations.

Thomas D. Sigerstad is a doctoral student at the University of Oklahoma. Mr. Sigerstad's primary areas of interest are in strategic management with a special emphasis on social issues in management. His current work involves the institutional process of legitimation and developing legitimacy as a meta-construct. He spent more than two decades in industry prior to entering the doctoral program. 